Bedim, B.P.; Tubaldini, M.A.S.; Nogueira, L.S. A comercialização do queijo canastra aos visitantes do Parna Serra da Canastra: estimativas de gasto, percentuais de compra e benefícios às propriedades rurais da zona de amortecimento do Parque. Anais do VIII Congresso Nacional de Ecoturismo e do IV Encontro Interdisciplinar de Ecoturismo em Unidades de Conservação. Revista Brasileira de Ecoturismo, São Paulo, v.4, n.4, 2011, p. 521.

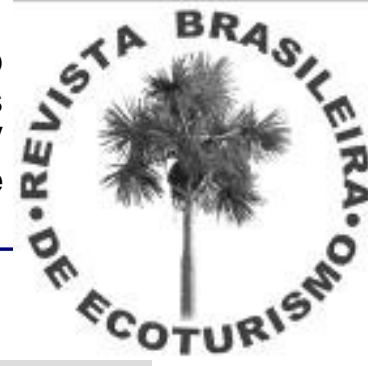

\title{
A COMERCIALIZAÇÃO DO QUEIJO CANASTRA AOS VISITANTES DO PARNA SERRA DA CANASTRA: ESTIMATIVAS DE GASTO, PERCENTUAIS DE COMPRA E BENEFÍCIOS ÀS PROPRIEDADES RURAIS DA ZONA DE AMORTECIMENTO DO PARQUE
}

\section{Bruno Pereira Bedim*, Maria Aparecida dos Santos Tubaldini**, Luana Soares Nogueira*}

*Universidade Federal de Ouro Preto, ${ }^{* *}$ Universidade Federal de Minas Gerais

E-mails: brunobedim@yahoo.com.br, ubaldini1@uol.com.br, lusoares56@yahoo.com.br

Esta pesquisa tem por objetivo mensurar o impacto econômico decorrente da compra do Queijo Canastra por turistas que visitam o Parque Nacional da Serra da Canastra. Para alcançar os resultados esperados, foi elaborado um formulário com questões relativas à aquisição do queijo canastra pelos visitantes do Parque. Primeiramente, perguntou-se se o entrevistado comprou o queijo Canastra e por quê. $\mathrm{Na}$ seqüência, informações complementares foram coletadas, tais como: i) Quantidade de queijos comprados; ii) Preço por unidade; iii) Local de compra (anota-se o nome do estabelecimento e a localização); iv) Fonte da indicação (quem indicou) o estabelecimento de compra do queijo. Foram entrevistados 490 visitantes do PARNA Serra da Canastra entre os meses de junho e outubro de 2010. O modelo de amostragem adotado consiste na amostra probabilística por tráfego ou acidental, onde cada elemento da população (turista) teve a mesma probabilidade de ser entrevistado e, portanto, de estar incluído na amostra. A pesquisa possui uma margem de erro de 5 pontos percentuais, para mais ou para menos portanto alcança uma confiabilidade de $95 \%$. Os dados apontam que $71,5 \%$ dos visitantes do Parque compram o queijo canastra diretamente dos produtores locais, sendo que cada turista adquiriu, em média, $2,8 \mathrm{Kg}$ do produto. O preço médio pago pelo $\mathrm{Kg}$ de queijo é $\mathrm{R} \$ 11,68$. A partir dos dados empíricos coletados, estima-se que 24.202 visitantes do Parque compraram o queijo Canastra em 2010, resultando na venda de $69.564 \mathrm{Kg}$ de queijo. A projeção da receita bruta anual gerada pela venda do queijo aos visitantes do parque é de $R \$ 812.507,52$. Desde a abertura do Parque da Canastra à visitação pública, o turismo tem possibilitado a diversificação das atividades produtivas nas propriedades rurais do entorno do parque, haja vista as possibilidades de inserção econômica dos produtores rurais no setor de hotelaria, alimentação, guias, entre outros potenciais serviços prestados diretamente aos turistas. Entre os principais resultados, a pesquisa aponta que a venda de queijo Canastra diretamente aos turistas permite a eliminação da figura do atravessador (ou queijeiro), aumentando assim os ganhos dos produtores.O Queijo da Serra da Canastra é produzido a partir do leite cru, totalmente artesanal, o qual se tornou um marco na cultura mineira. O Queijo possui um valor indentitário na cultura das Minas e é considerado patrimônio nacional reconhecido pelo IPHAN. Alguns dos camponeses que tem uma vantagem locacional de suas fazendas e sítios fizeram pequenas mudanças em suas propriedades para que possam receber os turistas, em camping, ou até mesmo em um quarto da residência. Essas melhorias não se limitam à estrutura da casa e do entorno, mas também, no caso dos produtores de queijo, em novas para que os turistas tenham uma boa imagem de seu produto.

Palavras-chave: Parque Nacional; Serra da Canastra; Queijo. 